\title{
Comparison of the Adrenocorticotrophic Activities of Two Synthetic Polypeptides: Synacthen and DW 75*
}

\author{
W. W. DOWNIE, M.B., B.SC. ; K. WHALEY, M.B. ; MARY A. WRIGHT, M.B. \\ MARGARET A. BELL, A.I.M.L.T.; ANNE K. TAYLOR, A.I.M.L.T.
}

Brit. med. F., 1968, 4, 487-489

Cummary : The adrenocorticotrophic activities of two synthetic polypeptides, Synacthen (Ciba) and DW 75 (Sandoz), were compared in two groups of patients having a variety of arthritic disorders. Compared with Synacthen, injected either intramuscularly or intravenously, intravenous DW 75 was found to have a longer duration of adrenocorticotrophic activity (measured by plasma 11-hydroxycorticosteroid levels) in both groups of patients, while intramuscularly administered DW 75 did not appear to be absorbed well.

\section{Introduction}

Since the elucidation of the chemical structure of naturally occurring adrenocorticotrophic hormone (A.C.T.H.) by Bell (1954), various synthetic polypeptides have been produced which demonstrate adrenocorticotrophic activity both in vitro and in vivo. The biological potency in vitro, determined by the adrenal ascorbic acid depletion test (Sayers et al., 1948) of a synthetic A.C.T.H. containing the 39 amino-acids known to occur in the natural hormone (Schwyzer and Sieber, 1963), was found to be 115 i.u./mg. Comparable activity (106 i.u./ mg.) was found when using the $\beta^{1-24}$ synthetic corticotrophin of Kappeler and Schwyzer (1961). This latter compound is available commercially as Synacthen (Ciba), and has become accepted as a useful means of investigating adrenocortical function (Wood et al., 1965 ; Greig et al., 1966).

Another polypeptide with adrenocorticotrophic activity has recently been synthesized by Boissonnas et al. (1966). Containing 25 amino-acids, it showed three modifications of the sequence of amino-acids in natural A.C.T.H.: D-serine was introduced in place of $\mathrm{L}$-serine at the $\mathrm{N}$-terminal to increase resistance against degradation by aminopeptidases, valinamide was substituted for asparagine in position 25 to increase resistance against degradation by carboxypeptidases, and norleucine was incorporated in place of methionine in position 4 , since it is known that oxidation of methionine results in inactivation. D-Serine ${ }^{1}$ - norleucine $\mathrm{C}^{4}$ - valinamide $^{25}-\beta^{1-25}$ corticotrophin (DW 75, Sandoz) has been shown to have a biological potency in vitro of $625 \mathrm{i} . \mathrm{u} . / \mathrm{mg}$. - that is, almost six times that of natural A.C.T.H. and the synthetic analogue Synacthen (Doepner, 1966). Because of the specific substitutions in the molecule it was thought that the duration of activity of the compound would be greater than that of natural A.C.T.H. and Synacthen. In-vivo studies in man by Jenny et al. (1966) have shown considerable adrenocorticotrophic activity after intravenous, intramuscular, and subcutaneous injection of DW 75.

The purpose of the present study was to compare the adrenocorticotrophic effects of Synacthen and DW 75 administered by intravenous and intramuscular injection.

- From the Centre for Rheumatic Diseases, Baird Street, and the University Department of Medicine, Royal Infirmary, Glasgow C.4.

\section{Methods}

Seventeen subjects were studied. All were inpatients in the Centre for Rheumatic Diseases, 10 of whom had a variety of rheumatic disorders but had never received corticosteroid therapy and had no clinical or laboratory evidence of endocrinopathy. The remaining seven had rheumatoid arthritis for which they had received corticosteroid drugs, resulting in suppression of adrenocortical function as judged by a subnormal 30-minute Synacthen test.

In the first group intramuscular and intravenous injections of $250 \mu \mathrm{g}$. of Synacthen and intramuscular and intravenous injections of $40 \mu \mathrm{g}$. of DW 75 were given. These doses are considered to be equivalent on the basis of the in-vitro potency values. Each patient had all four procedures with an interval of 48 hours between successive injections. The corticotrophins were administered in a random order.

Each patient in the second (corticosteroid-treated) group received $250 \mu \mathrm{g}$. of Synacthen by the intramuscular route and $40 \mu \mathrm{g}$. of DW 75 intravenously, with 48 hours between each injection, and once more the order of administration was randomized. It was thought that these two procedures would be sufficient to demonstrate any significant difference in the effects of the two compounds under study. All intramuscular injections were administered in the gluteal region.

All procedures were begun at 8 a.m. with the patient resting quietly in bed and remaining in bed for the duration of the investigation. Blood samples were removed for plasma 11-hydroxycorticosteroid (11-OHCS) estimation immediately before injection of the corticotrophin and at 30 and 60 minutes, and two, four, and six hours after injection. Plasma 11-OHCS was also estimated at 12 hours during procedures involving DW 75, since the duration of activity of the compound is not known.

Reproducibility of the DW 75 results was investigated in a further six patients who had never received corticosteroid drugs. DW 75 was injected intravenously on two separate occasions and 11-OHCS levels were measured as already described.

Plasma 11-OHCS levels were determined by the standard fluorimetric method of Mattingly (1962).

\section{Results}

The plasma 11-OHCS levels after administration of synthetic corticotrophin are shown in Tables I to III.

In the non-steroid-treated subjects the mean basal levels before Synacthen stimulation were 24.0 and $24.4 \mu \mathrm{g} . / 100 \mathrm{ml}$. before intravenous and intramuscular administration respectively, and subsequent values were also very similar, the peak occurring at two hours, irrespective of the route of injection of Synacthen (Table I). There was no significant difference between the mean levels of plasma 11-OHCS at any time and a return to baseline levels was noted after six hours.

The mean 11-OHCS levels before administration of DW 75 were 27.0 and $26.6 \mu \mathrm{g}$. $/ 100 \mathrm{ml}$. for the intravenous and intra- 
muscular routes respectively. Subsequent values are shown in Table i. Following intravenous injection of this corticotrophin a mean maximum value for 11-OHCS of $69.7 \mu \mathrm{g} . /$ $100 \mathrm{ml}$. was found after two hours and the levels remained raised at four and six hours, compared with those produced by intravenous Synacthen, with a return to baseline levels after 12 hours. A mean maximum value of $43.1 \mu \mathrm{g} . / 100 \mathrm{ml}$. after intramuscular injection of DW 75 was obtained at 30 minutes, with a gradual return to baseline values after six hours.

Reproducibility of results following intravenous DW 75 is shown in Table II. Into six subjects $40 \mu \mathrm{g}$. of DW 75 was injected on two occasions 48 hours apart as previously described and serial plasma 11-OHCS estimations were made. There was no significant difference between the levels of 11-OHCS at any time during the procedure, except at the beginning of the experiment $(0$ minutes). This can probably be explained on the basis of mild apprehension on the part of the subjects involved before injection on the first occasion.

Table III shows the results obtained in the group of patients who had received corticosteroid therapy and who were considered to have secondary adrenal atrophy on the basis of a subnormal 30-minute Synacthen test, using the criteria of Greig et al. (1968). According to these authors a normal Synacthen test is represented by a basal level of 11-OHCS of 6-26 $\mu \mathrm{g} . / 100 \mathrm{ml}$. , an increment of $7-25 \mu \mathrm{g} . / 100 \mathrm{ml}$. , and a $30-$ minute value of $18-47 \mu \mathrm{g} . / 100 \mathrm{ml}$. So far as the nature and continuity of corticosteroid therapy are concerned, the mean duration of treatment was 4.7 years and the average daily dose was about $10 \mathrm{mg}$. of prednisolone equivalent. The subjects were still receiving corticosteroid therapy, but the morning dose was omitted on the day of the test procedure. After intramuscular injection of $250 \mu \mathrm{g}$. of Synacthen the plasma 11OHCS levels rose from a mean baseline value of $4.7 \mu \mathrm{g} . / 100$ $\mathrm{ml}$. to a peak at two hours of $15.7 \mu \mathrm{g} . / 100 \mathrm{ml}$. and returned to $6 \mu \mathrm{g} . / 100 \mathrm{ml}$. after six hours. After intravenous administration of $40 \mu \mathrm{g}$. of DW 75 a mean maximum value of $18.6 \mu \mathrm{g}$./ $100 \mathrm{ml}$. was obtained, the mean value before corticotrophin injection being $3.4 \mu \mathrm{g} . / 100 \mathrm{ml}$. The mean values of $11-\mathrm{OHCS}$ during the two hours after administration of either Synacthen or DW 75 were not significantly different, but the four- and six-hour values after DW 75 were significantly higher than those found at these times after Synacthen. In addition, the 9- and 12-hour values after DW 75 were still significantly higher than the baseline level.

No side-effects were noted in any of the patients who received DW 75 either intravenously or intramuscularly.

\section{Discussion}

The adrenocorticotrophic activity of Synacthen has been well documented by other workers (Landon et al., 1964 ; Wood et al., 1965 ; Greig et al., 1966). The virtually identical patterns of plasma 11-OHCS response following injection of the polypeptide by the intravenous and intramuscular routes suggest rapid and almost complete absorption from the intramuscular site of administration.

DW $75 \beta^{1-25}$ corticotrophin has a potent adrenocorticotrophic action in man when administered intravenously. The high levels of circulating 11-OHCS in normal subjects probably reflect a longer duration of action of the corticotrophin rather than more potent stimulation of the adrenal cortex, since it has been shown that supramaximal stimulation of the gland is obtained with $250 \mu \mathrm{g}$. of Synacthen (Greig et al., 1968). In addition, the slopes of the curves during the first 30 minutes, when the rate of change of 11-OHCS levels is greatest, are not significantly different when intravenous DW 75 or Synacthen (by either route) is used. We have also found that higher doses of DW 75-for example, 80,160, and $320 \mu \mathrm{g}$. intravenouslydo not alter the 30 -minute levels of $11-\mathrm{OHCS}$, indicating supramaximal stimulation of the adrenal cortex by $40 \mu \mathrm{g}$. of DW 75 (unpublished observations). The most likely explanation for the longer duration of activity of the compound is that degradation by tissue enzymes is slower as a result of the specific modifications introduced into the molecule during synthesis. The effect of intravenous injection of DW 75 has been shown to be entirely reproducible.

The apparent failure of intramuscularly administered DW75 to produce plasma levels of 11-OHCS comparable to those following Synacthen stimulation requires some explanation. It is not the result of temporary adrenal insufficiency, since the procedures were performed in a random order in all patients, with 48 hours between successive injections of corticotrophin. Inactivation of the compound in the tissues seems unlikely, since the modifications introduced into the molecule were specifically incorporated to reduce enzymatic degradation. Further evidence against this suggestion comes from the lack of discrepancy in the results following intramuscular and intravenous injection of Synacthen, since one would reasonably assume that degradation of Synacthen and DW 75 would be accomplished by similar enzymatic pathways.

The final possibility considered was that of defective absorption. It may be that the alterations in the molecule, designed to protect the polypeptide from enzymatic breakdown, have so altered the absorption characteristics that intramuscularly

\begin{tabular}{|c|c|c|c|c|c|c|c|c|c|}
\hline \multirow{2}{*}{ Drug } & \multirow{2}{*}{ Route } & \multicolumn{8}{|c|}{ Plasma 11-OHCS: Mean \pm S.E. $(\mu \mathrm{g} . / 100 \mathrm{ml})}$. \\
\hline & & $0 \mathrm{~min}$. & $30 \mathrm{~min}$. & $60 \mathrm{~min}$. & 2 Hours & 4 Hours & 6 Hours & 9 Hours & 12 Hours \\
\hline $\begin{array}{l}\text { Synacthen } \\
\text { DW 75 }\end{array}$ & $\begin{array}{l}\text { I.M. } \\
\text { I.V. }\end{array}$ & $\begin{array}{l}4 \cdot 7 \pm 1 \cdot 17 \\
3.4 \pm 0.80\end{array}$ & $\begin{array}{l}12.4 \pm 1.69 \\
13.8 \pm 1.63\end{array}$ & $\begin{array}{l}13.9 \pm 2.38 \\
16.0 \pm 1.36\end{array}$ & $\begin{array}{l}15 \cdot 7 \pm 2 \cdot 11 \\
18.6 \pm 2.79\end{array}$ & $\begin{array}{r}7.3 \pm 1.89 \\
12.5 \pm 1.79\end{array}$ & $\begin{array}{r}6.0 \pm 1.96 \\
13.7 \pm 3.06\end{array}$ & $11 \cdot \overline{6 \pm 2}$ & $8.4 \overline{3} .72$ \\
\hline
\end{tabular}


administered DW 75 is not absorbed with sufficient rapidity nor in sufficient quantity to be of any value in assessing adrenocortical integrity.

The significance of the relatively high levels of plasma 11OHCS at four and six hours after intravenous administration of DW 75 in the steroid-treated subjects again probably reflects the longer duration of this compound compared with that of Synacthen.

Our results have confirmed those of Jenny et al. (1966) that DW 75 has powerful adrenocortical stimulating properties. However, these workers also found that intramuscular injection of the compound resulted in a sustained rise in plasma 11-OHCS similar to that following intravenous administration. It is obvious that more subjects will have to be studied in order to resolve this discrepancy.

DW 75 has no obvious advantages over Synacthen in assessing adrenocortical function on the basis of a 30-minute test, nor can its duration of action compare with that of Synacthen Depot (Besser et al., 1967 ; Nelson et al., 1968), but its intermediate duration of activity may be useful in assessing depressed adrenals without priming the glands as could well happen with the long-acting preparations of corticotrophin.

We wish to thank Dr. W. Watson Buchanan and Dr. J. A. Boyle for advice and helpful criticism. The work was supported in part by a grant from the Arthritis and Rheumatism Council. We are grateful to Dr. D. S. Freestone, of Sandoz Ltd., for supplies of DW 75.

\section{REFERENCES}

Bell, P. H. (1954). 7. Amer. chem. Soc., 76, 5565.

Besser, G. M., Butler, P. W. P., and Plumpton, F. S. (1967). Brit. med. f., 4, 391 .

Boissonnas, R. A., Guttmann, S., and Pless, J. (1966). Experientia (Basel), 22, 526.

Doepfner, W. (1966). Experientia (Basel), 22, 527.

Greig, W. R., Browning, M. C. K., Boyle, J. A., and Maxwell, J. D. (1966). \%. Endocr., 34, 411.

Greig, W. R., Jasani, M. K., Boyle, J. A., and Marwell, J. D. (1968). In The Investigation of Hypothalamic-pituitary-adrenal Function edited by V. H. T. James and J. Landon, p. 176. London.

Jenny, M., Muller, A. F., and Mach, R. S. (1966). Experientia (Basel), 22, 528.

Kappeler, H., and Schwyzer, R. (1961). Helv. chim. Acta, 44, 1136.

Landon, J., James, V. H. T., Cryer, R. J., Wynn, V., and Frankland, A. W. (1964). F. clin. Endocr., 24, 1206.

Mattingly, D. (1962). F. clin. Path., 15, 374.

Nelson, J. K., Neill, D. W., Montgomery, D. A. D., MacKay, J. S., Sheridan, B., and Weaver, J. A. (1968). Brit. med. F., 1, 557.

Sayers, M. A., Sayers, G., and Woodbury, L. A. (1948). Endocrinology, $42,379$.

Schwyzer, R., and Sieber, P. (1963). Nature (Lond.), 199, 172.

Wood, J. B., Frankland, A. W., James, V. H. T., and Landon, J. (1965). Lancet, 1, 243.

\title{
Contraceptive Action of Continuous Low Doses of Norgestrel
}

\author{
G. L. FOSS,* O.B.E., V.R.D., M.A., M.D. ; E. K. SVENDSEN, †§ M.D. ; K. FOTHERBY, † PH.D., F.R.I.C. \\ D. J. RICHARDS, $\ddagger$ M.B., CH.B., B.SC.
}

Brit. med. F., 1968, 4, 489-491

\begin{abstract}
Cummary : Norgestrel in a dose of $50 \mu \mathrm{g}$. was $\checkmark$ administered daily to 188 women during 2,250 menstrual cycles. Only two pregnancies occurred because of failure of the method, giving a failure rate of 1.1 pregnancies per 100 woman-years. The method was acceptable to most of the subjects, and side-effects, other than menstrual irregularity, were minimal ; $68 \%$ of the cycles were $28 \pm 5$ days in length and $21 \%$ were less than 23 days. There did not appear to be any increased incidence of amenorrhoea. The antifertility action of continuous administration of low doses of progestogen may be due to an effect on corpus luteum function, in addition to the effects on cervical mucus, endometrium, and tubal transport of ova. The optimum dose of norgestrel appears to be in the range of $50-75 \mu \mathrm{g}$./day.
\end{abstract}

\section{Introduction}

Martinez-Manautou et al. (1966, 1967) showed that continuous dosage with $0.5 \mathrm{mg}$. of chlormadinone acetate daily exerted an antifertility effect, though ovulation was not always inhibited. In a trial involving over 900 women for more than 8,000 cycles only one pregnancy occurred that could be attri-

* Clinical Assistant, Endocrine Clinic, United Bristol Hospitals, and Head of Bristol Male Sub-Fertility Clinic.

t Department of Steroid Biochemistry, Royal Postgraduate Medical School, London W.12.

$\ddagger$ Head of Clinical Investigation, John Wyeth \& Brother Ltd., Taplow, Maidenhead.

$\$$ Present address: Department of Obstetrics and Gynaecology, University of Bergen, Norway. buted to a failure of the method, giving a pregnancy rate of 0.2 per 100 woman-years. The Sims-Huhner test was negative in $80 \%$ of 115 women studied, and $65 \%$ of the endometrial biopsies from 202 women showed normal or irregular secretory patterns indicative of ovulation. Other studies in which the same dose of chlormadinone was used have shown a failure rate of 4.6 per 100 woman-years (Zañartu et al., 1968). The antifertility effect of low-dose progestogen treatment was ascribed to effects on the uterine endometrium or to effects on cervical mucus. The above studies involving chlormadinone acetate were carried out on South and Central American women, and it was felt desirable to test the acceptability of this type of method in British women. The results of the present paper show that norgestrel (13 $\beta$-ethyl-17 $\alpha$-ethynyl-17 $\beta$-hydroxygon4-en-3-one), a totally synthetic steroid and one of the most potent progestogens available, at a dose level of $50 \mu \mathrm{g} . /$ day exerts an antifertility effect.

\section{Subjects and Methods}

The patients admitted to the trial were seen regularly at monthly intervals; at the initial attendance the subjects were examined and information was obtained regarding parity, menstrual history, previous methods of contraception, and general medical history. Care was taken to explain in detail the method to be used. At each monthly visit details of menstruation, weight changes, possible side-effects, and other relevant data were recorded on specially printed cards. Bleeding that was not different in amount or duration from the usual pattern was recorded as menstruation. Endometrial biopsies 